\title{
Using the Viable System Model to Study IT Governance Dynamics: Evidence from a Single Case Study
}

\author{
Tim Huygh \\ University of Antwerp, \\ Antwerp, Belgium \\ Tim.huygh@uantwerpen.be
}

\author{
Steven De Haes \\ University of Antwerp, \\ Antwerp, Belgium \\ Steven.dehaes@uantwerpen.be
}

\begin{abstract}
This paper presents a single descriptive case study in which the viable system model (VSM) is used as a theoretical lens to model an organization's contemporary IT governance system. The case presented herein was selected specifically for being a digitized company of which we knew that a lot of effort was put recently in their IT governance system. We find that the case company's IT governance system maps well to the structure and underlying logic of the VSM. This paper contributes to the literature by providing an empirical justification exemplar on the applicability of systemic thinking in general, and the VSM in specific, for modelling enterprise governance and management of IT.
\end{abstract}

\section{Introduction}

It is a well-established fact that organizations are becoming more and more dependent on IT. As a result of continuous technological progression, organizations are faced with a plenitude of IT-related opportunities that might be helpful in increasing their operational efficiency and/or generating competitive advantage [1]. Digital disruption is all around us, and many organizations are actively thinking about such transformations [2]. Disruptive technologies can impact business models, or even entire sectors in short timeframes [3]. Given an increasing dependency on IT, decision-makers are faced with more IT-related decisions [4]. Disciplines like IT management and IT governance surfaced to assist decision-makers with these issues [5], [6]. It has been stressed many times that the effective use of IT and the creation of business value from IT relies heavily on good IT governance [4], [7]-[9]. Specifically, IT governance is said to have a substantial impact on the value generated from IT assets and IT investments. As Weill \& Ross [7, pp. 34] put it: "effective IT governance is the single most important predictor of the value an organization generates from IT." Next to the potential benefits of good IT governance, there are also potential risks to nonexistent or inappropriate IT governance. IT governance failure is for instance mentioned in relation to information security breaches and IT investment failure [10], [11]. In summary, contemporary organizations have clear incentives to strive for effective IT governance, especially if their dependency on IT is high.

This study aims to explore an effort to bring in more theory and prescriptive guidance in the area of IT governance. More specifically, the goal of this study is to gauge the applicability of using the viable system model (based on the theory of management cybernetics) as a lens to study the IT governance construct, by presenting a descriptive case study that leverages this lens. As a result, this study proposes to view IT governance as a complex system. Complex systems exist in a dynamically changing environment that demands dynamically responding behavior, i.e. they must possess the ability to adapt to their environment [12], for instance due to digital disruption. Following Conant \& Ashby [13], in order to be able to control a (complex) system, there must be a model of the system that is to be controlled, and this model must contain all important aspects of that system. In the present paper, the viable system model, grounded in (management) cybernetics, will be used as a lens for modelling the governance and management of IT. This way, cybernetics is used as a kernel theory, providing a strong theoretical foundation. If we propose the VSM to be applicable for modelling a governance and management of IT system, a prescriptive account will be provided following the VSM logic on which functions should be included in any IT governance system and how they should be interrelated, as well as the dynamics that emerge within such a system. The larger descriptive body of IT governance literature can then be used as good practices to operationalize said necessary and sufficient functions, following the prescriptions provided by the VSM, in an appropriate context (e.g. SME context, inter-organizational context etc.). 
The VSM has been applied in IS research before [14]. While the VSM is traditionally used to model organizations (i.e. taking the organization as "systemin-focus”), IS research applied the VSM to a variety of socio-technical systems. Examples include a project management system [15], complex system architecture [12], a supply chain system [16], information security [17], and IT governance [18][20]. Indeed, the VSM has been used in relation to IT governance before, albeit strictly conceptually. The present research builds on these previously-proposed ideas. Specifically, this paper presents an empirical justification exemplar of the application of the VSM for modelling an organization's contemporary governance and management of IT system and explicitly describes the observed dynamics in terms of the underlying logic of the VSM.

The remainder of this paper is structured as follows. Section 2 contains the theoretical background for this research, ending with a theoretical justification of the applicability of systemic thinking and the VSM for modelling a governance and management of IT system. The third section discusses the research design and provides some information on how the case study was conducted. Section 4 presents aspects of the case company's contemporary governance and management of IT system, using the VSM as a theoretical lens. This section also includes a discussion of the dynamics of the case company's contemporary governance and management of IT system, related to the underlying logic of the VSM. Finally, the fifth section presents some limitations and opportunities for future research.

\section{Theoretical background}

\subsection{IT governance}

IT governance should be treated as a focal area of corporate governance [4], [7]. Van Grembergen \& De Haes [21, p. 3] define the concept as "an integral part of corporate governance and addresses the definition and implementation of processes, structures and relational mechanisms in the organization that enable both business and IT people to execute their responsibilities in support of business/IT alignment and the creation of business value from IT-enabled business investments". Over time, IT governance gained momentum due to more companies becoming increasingly dependent on IT for their strategic and operational business activities [4], [22].
In the IT governance body of knowledge, many different mechanisms are reported, such as strategy committees, steering committees, a portfolio management process, etc. [7], [23]-[25]. Early debates merely framed IT governance as a choice between the centralization or decentralization (or a combination of both) of IT-related decision-making, and the conditions under which a certain arrangement was chosen [26]-[28]. The experience however, has proven that reality is more complex, and research into 'holistic' IT governance has been gathering momentum over the last decade [4], [7], [8], [23], [24], [29], [30]. Specifically, contemporary research states that IT governance can be implemented using a holistic set of structures, processes, and relational/communication mechanisms [24], [30]. It is exactly this holistic nature of IT governance as a set of mechanisms that lends itself well to the application of systemic thinking. Additionally, taking a (complex) systems approach, the dynamic nature of IT governance systems is acknowledged. This study therefore proposes a dynamic way of looking at the IT governance concept, while still acknowledging the holistic state-of-the-art view that sees IT governance as a set of practices.

\subsection{Systemic thinking and the viable system model}

A system consists of a set of interrelated elements [31] and is designed to serve a purpose [32]. This set of interrelated elements exists in the "system domain", which separates the system from the "environment". However, communication can take place between the system and the environment [32]. Complex systems exist in a dynamically changing environment that demands dynamically responding behavior, i.e. they must possess the ability to adapt to their environment [12]. Systemic thinking advocates a holistic view on the whole system as a set of elements and the analysis of the relationships between these elements [33], as these may lead to emergent properties that are even more important than the individual elements themselves [34].

Flood \& Jackson [35] discuss a number of systemic methodologies to study (complex) systems. One of these methodologies is the viable system view or "neurocybernetic metaphor". This methodology emphasizes active learning and control and is therefore particularly useful for systems that are operating in highly uncertain environments. Systemic methodologies generally rely heavily on visual representation. The Viable System Model (VSM) is the visual representation of the viable system view or 
“neurocybernetic metaphor”. Stafford Beer developed and described the VSM in his seminal trilogy, under the general heading of "The managerial cybernetics of organization" [36]-[39]. The VSM is theoretically grounded in systems theory and cybernetics. Building on prior work in the field of cybernetics, Beer is talking about "management cybernetics" [40], which simply refers to applying cybernetic principles to the management of organizations, and states that: "cybernetics is the science of effective organization" [38, p. ix]. As a result, the VSM can be referred to as "a theory of organization" [41, p. 40]. Stafford Beer is considered to be the first to translate cybernetic principles to the field of management, ultimately resulting in the VSM [42]. Beer's motivation is stemming from the fact that traditional ways of thinking about the management of organizations do not embrace the key concept of viability [38].

Table 1 first presents the key underlying concepts of the VSM. Viability can be seen as the ultimate underlying concept of the VSM. It means that the system is able to continue achieving its purpose, despite being exposed to complexity/change. The five systems (i.e. systems 1 through 5; discussed in the second part of the table) are the necessary and sufficient subsystems that enable viability. These systems are interconnected through variety loops (discussed in the third part of the table) to enable variety engineering (i.e. achieving requisite variety). The concept of recursion is also important in variety engineering (i.e. it enables variety engineering at different levels of granularity), and therefore, ultimately in achieving viability. In terms of variety engineering, transduction is concerned with variety preservation while translating the message into terms that the receiving entity understands.

Table 1. VSM systems, variety loops, and key underlying concepts VSM key underlying concepts

\begin{tabular}{|l|l|}
\hline & VSM key underlying concepts \\
& The system is capable to maintain itself/its \\
identity [43]. This is closely related to the \\
concept of variety, as a system is said to be \\
viable when it is able to continuously cope \\
with the variety to which it is imposed [44]. \\
Therefore, a system can only be viable if it \\
has its own problem-solving capacity [45]. \\
Indeed, for viable systems it is important to \\
detect environmental changes quickly and \\
adapt in a way to meet the variety to which \\
it is exposed at any given time [46].
\end{tabular}

\begin{tabular}{|c|c|}
\hline 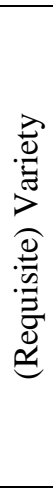 & $\begin{array}{l}\text { Variety is a measure of complexity [37]. } \\
\text { The ability to continuously cope with this } \\
\text { variety implies to be viable. Ashby's law } \\
\text { of requisite variety is a fundamental } \\
\text { underlying principle of the VSM. The law } \\
\text { states that only variety can absorb variety } \\
\text { [47, p. 207]. In other words, the variety of } \\
\text { the controlling element should be at least } \\
\text { as great as the variety of the element that is } \\
\text { to be controlled. Therefore, variety } \\
\text { engineering takes place at each } \\
\text { "communication channel" of the VSM. }\end{array}$ \\
\hline 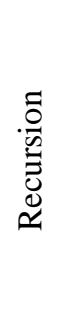 & $\begin{array}{l}\text { Recursion refers to the fact that "any } \\
\text { viable system contains, and is contained in, } \\
\text { a viable system" [37, p. 118]. Each } \\
\text { embedded viable system will deal with its } \\
\text { local environment, which is a subset of the } \\
\text { total environment of the system-in-focus } \\
\text { [45]. This enables consistent modelling at } \\
\text { different levels of granularity. }\end{array}$ \\
\hline 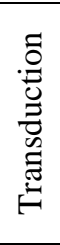 & $\begin{array}{l}\text { Transduction applies to the } \\
\text { communication links of the VSM. It } \\
\text { implies that the communication between } \\
\text { two entities should be translated into terms } \\
\text { that the receiving entity understands, while } \\
\text { preserving the intended variety [38]. }\end{array}$ \\
\hline & VSM systems \\
\hline & $\begin{array}{l}\text { System } 1 \text { is composed of all relevant } \\
\text { operations that implement the purpose of } \\
\text { the system, and all local managerial } \\
\text { activity related to running these operations. } \\
\text { System } 1 \text { of the system-in-focus is } \\
\text { therefore the combination of all embedded } \\
\text { viable systems [37], [38]. }\end{array}$ \\
\hline 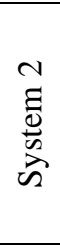 & $\begin{array}{l}\text { System } 2 \text { coordinates the system } 1 \\
\text { activities of the system-in-focus, as well as } \\
\text { their embedded operations at the next } \\
\text { lower-level recursion [37]. It represents a } \\
\text { process of auto-regulation to deal with } \\
\text { oscillations. }\end{array}$ \\
\hline 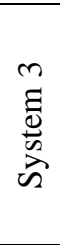 & $\begin{array}{l}\text { System } 3 \text { controls the operation of the } \\
\text { system-in-focus (i.e. system 1; all } \\
\text { embedded viable systems) [38]. It is } \\
\text { responsible for keeping the autonomy of } \\
\text { all S1-units in balance with the overall } \\
\text { cohesion of the system-in-focus [41]. }\end{array}$ \\
\hline 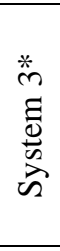 & $\begin{array}{l}\text { System } 3^{*} \text { is the audit or monitoring } \\
\text { channel, and links all operational units } \\
\text { directly to system } 3 \text {, bypassing their local } \\
\text { management units, enabling system } 3 \text { to } \\
\text { obtain information directly from } \\
\text { operations [38]. }\end{array}$ \\
\hline
\end{tabular}




\begin{tabular}{|c|l|}
\hline & $\begin{array}{l}\text { System 4 scans for opportunities and } \\
\text { threats in the system's environment, which } \\
\text { could potentially threaten the system's } \\
\text { viability if they were to be undetected [45]. }\end{array}$ \\
$\begin{array}{l}\text { Additionally, it is engaged in external } \\
\text { communication with the total environment } \\
\text { of the system-in-focus [38]. }\end{array}$ \\
\hline VSM
\end{tabular}

To summarize, it can be seen that the VSM is a dynamic model to support the design and diagnosis of effective control and communication structures [34], rigorously anchored in the theory of cybernetics.

\subsection{Theoretical parallels between the VSM and IT governance}

In the context of this paper, the governance and management of IT will be regarded as a complex system. Taking a systemic view warrants a holistic view on the IT governance construct, which is entirely in line with contemporary research in the domain, which sees IT governance as a holistic set of structures, processes, and relational mechanisms. Taking a systemic view also requires to think about the purpose of IT governance. The ultimate purpose of IT governance is generally seen as optimizing the business value from IT, while simultaneously mitigating IT-related risks. Furthermore, the key underlying concepts of the VSM in specific (viz. Table 1), also translate well to the construct of IT governance at the conceptual level (First part of Table 2). This table furthermore presents the relevance of the structural part of the VSM (i.e. systems and variety loops) in relation to IT governance.

Table 2. Theoretical parallels between the VSM and IT governance

\begin{tabular}{|c|c|}
\hline & $\begin{array}{l}\text { VSM underlying concepts and the } \\
\text { relevance to IT governance }\end{array}$ \\
\hline 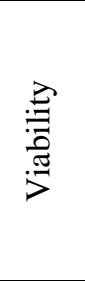 & $\begin{array}{l}\text { An IT governance system needs to be able } \\
\text { to actively detect potential strategic threats } \\
\text { and opportunities in a business } \\
\text { environment that is subject to digital } \\
\text { disruption [3], to be able to continue } \\
\text { ensuring the delivery of IT-enabled } \\
\text { business value [4]. }\end{array}$ \\
\hline 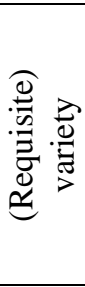 & $\begin{array}{l}\text { Digital disruption is a major source of } \\
\text { variety/complexity in the realm of the } \\
\text { governance and management of IT [3]. } \\
\text { Requisite variety is then the capability of } \\
\text { the system to control these disturbances } \\
\text { and continuously ensuring the delivery of } \\
\text { IT-enabled business value. }\end{array}$ \\
\hline 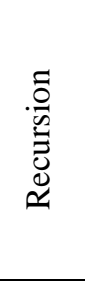 & $\begin{array}{l}\text { The governance and management of IT } \\
\text { should occur at different levels of } \\
\text { granularity within the organizational } \\
\text { context [4], [23]. For instance, at the inter- } \\
\text { organizational level, at the corporate level, } \\
\text { at the business domain-level, at the project } \\
\text { level, at the project task-level, etc. }\end{array}$ \\
\hline 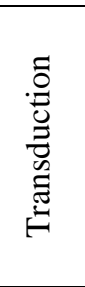 & $\begin{array}{l}\text { In order to ensure business/IT alignment, } \\
\text { generally considered to be a mediator } \\
\text { between IT governance and business value } \\
\text { [8], shared understanding between business } \\
\text { and IT is crucial [49]. This enables business } \\
\text { and IT to communicate clearly with each } \\
\text { other. }\end{array}$ \\
\hline & the \\
\hline
\end{tabular}




\begin{tabular}{|c|c|}
\hline 泀 & $\begin{array}{l}\text { The implementation of the purpose of the } \\
\text { governance and management of IT can be } \\
\text { argued to be the set of digital assets. Often, } \\
\text { a distinction is made between current (i.e. } \\
\text { operations) and future (i.e. projects) IT } \\
\text { assets. }\end{array}$ \\
\hline 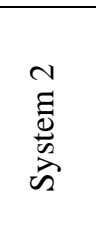 & $\begin{array}{l}\text { The coordination between different } \\
\text { (classes of) digital assets. Self-regulation } \\
\text { could for instance be achieved by using IT- } \\
\text { related standards or frameworks (e.g. } \\
\text { Prince2 for project management or ITIL for } \\
\text { IT service management). }\end{array}$ \\
\hline$\sum_{\substack{\infty \\
\infty}}^{m}$ & $\begin{array}{l}\text { Responsible for controlling the total set of } \\
\text { digital assets (i.e. S1). Specific } \\
\text { responsibilities include resource } \\
\text { management, performance measurement, } \\
\text { and enforcing IT-related policies (cfr. } \\
\text { "command axis"). }\end{array}$ \\
\hline 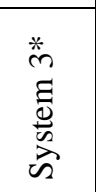 & $\begin{array}{l}\text { IT-related audits (e.g. project audit, } \\
\text { security audit etc.) }\end{array}$ \\
\hline 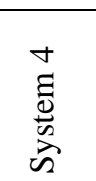 & $\begin{array}{l}\text { Technology scanning, keeping up with } \\
\text { emerging technologies, anticipating the } \\
\text { future of digital assets. }\end{array}$ \\
\hline 品 & $\begin{array}{l}\text { Defining the role of IT for the organization } \\
\text { (e.g. "IT as a strategic partner"), as well as } \\
\text { defining and maintaining IT governance } \\
\text { policies that logically follow this role of IT. }\end{array}$ \\
\hline \multicolumn{2}{|r|}{$\begin{array}{l}\text { VSM communication channels/variety loops } \\
\text { and the relevance to IT governance }\end{array}$} \\
\hline 导 & $\begin{array}{l}\text { IT resource management, IT performance } \\
\text { measurement, and enforcing IT-related } \\
\text { policies. }\end{array}$ \\
\hline 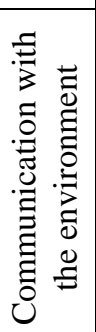 & $\begin{array}{l}\text { For instance: informing external } \\
\text { stakeholders on the way the organization is } \\
\text { governing and managing its IT-related } \\
\text { assets (i.e. IT governance transparency or } \\
\text { disclosure). }\end{array}$ \\
\hline 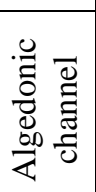 & $\begin{array}{l}\text { Raise alarm in the case of IT-related } \\
\text { incidents (e.g. security breach). }\end{array}$ \\
\hline
\end{tabular}

\begin{tabular}{|c|c|}
\hline 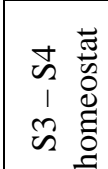 & $\begin{array}{l}\text { IT strategic planning and setting the IT } \\
\text { budget. }\end{array}$ \\
\hline
\end{tabular}

\section{Research methodology}

\subsection{Research approach}

This paper employs case study research to study the governance and management of IT system in a real organization, using the VSM as a theoretical lens. The case study method was deemed appropriate for our research goal, as it is applicable if a more extensive and in-depth study of the phenomenon of interest is required. The case study research process (and related guidelines) by Yin [50] was used for this research. Over the course of the case study, a chain of evidence was maintained and key interviewees were asked to review the research report to ensure construct validity. Reliability was ensured through the development of an interview protocol, recording the interviews, and using multiple interviewees (both business and IT), as well as data triangulation (interviews and company documents).

\subsection{Interviewees}

Over the course of this case study, the following stakeholders were interviewed:

- The CIO, who is ultimately responsible for the IT governance system. He originally developed the blueprint for the contemporary governance and management of IT system.

- $\quad$ The IT governance manager. This is a business function, with the main responsibility of watching over the IT governance processes.

- The managing director of "payroll services". This business domain has the largest IT budget for IT projects, and is therefore a major stakeholder in the IT governance system.

- The enterprise architect of the internal service domains. The EA is positioned as a bridge function between business and IT. The main responsibilities of this role include following-up on emerging technologies and long-term planning, as well as coordinating over the different business domains.

Each interview was conducted in a semi-structured fashion. All interviews were recorded and fully transcribed. The CIO was the sponsor of this case study at the organization, with whom four meetings 
were planned. Snowball sampling of other relevant interviewees was achieved through the CIO. The goal was to include key stakeholders in the governance and management of IT system, and to get a balanced perspective between the business and IT. The three other interviewees were only interviewed once. Each interview lasted between 45 and 90 minutes. Contradictory evidence in different interviews was verified with other stakeholders and ultimately with the CIO. Based on all of the collected evidence, the case company's governance and management of IT system was then modelled according to the VSM blueprint.

\section{Results}

In the following sections, we will briefly discuss (1) Acerta's background, (2) the mapping of Acerta's governance and management of IT practices to the VSM structure, and (3) the dynamics of Acerta's IT governance system using the underlying logic of the VSM.

\subsection{Introducing Acerta}

Acerta is an HR services provider in Belgium that specializes in advice, computerization and processing of administrative processes for payroll, social security, child benefits and branch formalities. Therefore, Acerta's customers are enterprises of all sizes, and self-employed workers. Acerta has more than 1,300 employees spread across 38 offices in Belgium. The firm had a turnover of just over 160 million euros in 2015. Acerta is not a publicly listed company. Instead, it is owned by two shareholders who each own $50 \%$ of the shares. In 2015, Acerta's total IT budget was 49 million euros. The estimate for 2016 is with 48 million euros approximately the same. The tendency since 2012 is that Acerta's IT budget lies between 40 and 50 million euros, as this can be supported by their contemporary cost structure. In 2015, са. $70 \%$ of the IT budget was used to "run the business" (i.e. "to keep the lights on”, including operational costs and small maintenance projects to maintain the existing portfolio), while ca. 30\% was used to "change the business" (i.e. projects for "new IT", both smaller and strategic). Again, the estimates for 2016 are approximately the same. In terms of IT costs, ca. 30\% of Acerta's total expenses are IT-related. Therefore, Acerta is very dependent on IT, especially on highly reliable operating systems. Acerta does however not claim to be a front-runner in the continuous application of emerging technologies (i.e. “new IT”).

\subsection{Acerta's IT governance practices mapped to the VSM systems and variety loops}

Analyzing the information extracted during case study research, we were able to map Acerta's governance and management of IT practices to the VSM systems and variety loops, in two different recursions (i.e. corporate level, and business domain level). Table 3 presents examples of this for the corporate level.

Table 3. Examples of corporate-level IT governance practices at Acerta (recursion 0) Examples of VSM systems manifest at Acerta

\begin{tabular}{|c|c|}
\hline 范 & $\begin{array}{l}\text { Activity Steering Committee (ASC) for each } \\
\text { business domain in charge of the } \\
\text { management of business domain IT assets. }\end{array}$ \\
\hline 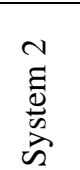 & $\begin{array}{l}\text { Enterprise Architecture Forum (EAF) for } \\
\text { coordinating the different business domain } \\
\text { IT assets, and supporting change } \\
\text { management for internal stakeholders. }\end{array}$ \\
\hline 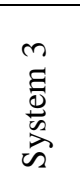 & $\begin{array}{l}\text { Enforcing hard legal \& corporate IT-related } \\
\text { requirements (e.g. IT-security requirements } \\
\text { enforced by the risk committee, i.e. using the } \\
\text { command axis). }\end{array}$ \\
\hline 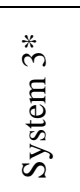 & $\begin{array}{l}\text { Externalized IT audit and IT crisis } \\
\text { simulations. }\end{array}$ \\
\hline 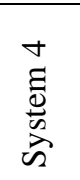 & $\begin{array}{l}\text { Enterprise Architecture Forum (EAF) } \\
\text { following up on emerging technologies and } \\
\text { their potential applications for Acerta. }\end{array}$ \\
\hline$\stackrel{n}{E}$ & $\begin{array}{l}\text { Board-level IT oversight: yearly } \\
\text { presentation of the IT strategy to the } \\
\text { supervisory board by the CIO, and IT- } \\
\text { related information part of monthly } \\
\text { performance reports (cfr. transduction). The } \\
\text { supervisory board also established a board- } \\
\text { level monitoring committee (and attached } \\
\text { steering committee) for "new wages } \\
\text { engine", a major strategic IT project. }\end{array}$ \\
\hline \multicolumn{2}{|r|}{$\begin{array}{l}\text { Examples of VSM variety loops manifest at } \\
\text { Acerta }\end{array}$} \\
\hline 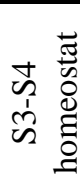 & $\begin{array}{l}\text { IT strategic planning and setting the IT } \\
\text { budget (long term plan) between EAF and } \\
\text { executive committee, overviewed by the } \\
\text { supervisory board. }\end{array}$ \\
\hline
\end{tabular}




\subsection{Studying IT governance at Acerta using the VSM's key underlying concepts}

\subsubsection{A recursive view on Acerta's governance and management of IT}

The VSM warrants a recursive view on a system. In this paper, we take Acerta's corporate IT governance system as recursion 0 , while recursion -1 would then deal with IT governance at the business domain level. Following the fractal nature of the VSM, each recursion consists of exactly the same building blocks. However, the operationalization of these elements will be different (as the focus of the recursion is different). Each recursion will deal with a different level of granularity. Therefore, new practices will be used to deal with the issues at a certain level. Accordingly, when moving down in recursions, we enter more and more in the area of IT management. We have briefly explored the governance and management of IT at the corporate level in Table 3. Examples of practices at the business domain level, mapped to the VSM systems and variety loops, are presented in Table 4. This clearly indicates the applicability of the concept of recursion to Acerta's governance and management of IT system.

Table 4. Examples of business domain-level IT governance practices at Acerta (recursion -1)

Examples of VSM systems manifest at Acerta

\begin{tabular}{|c|c|}
\hline$\sum_{\infty}^{\infty}$ & $\begin{array}{l}\text { Project steering committees (PSC) for } \\
\text { steering projects and maintenance steering } \\
\text { committees (MSC) for governing } \\
\text { maintenance budgets and priorities. }\end{array}$ \\
\hline 章 & $\begin{array}{l}\text { Release management for the coordination } \\
\text { and smooth transitioning from "change" to } \\
\text { "run". }\end{array}$ \\
\hline 焉 & $\begin{array}{l}\text { Activity Steering Committee (ASC), among } \\
\text { other things responsible for the division of } \\
\text { the business domain's IT budget according } \\
\text { to categories: investments, projects, } \\
\text { functional maintenance, and break \& fix. }\end{array}$ \\
\hline 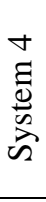 & $\begin{array}{l}\text { Domain council, chaired by the business } \\
\text { domain enterprise architect. This structure } \\
\text { for instance discusses new application } \\
\text { opportunities within the context of a } \\
\text { business domain. }\end{array}$ \\
\hline$\sum_{\infty}^{\infty}$ & $\begin{array}{l}\text { Business domain managing director, who } \\
\text { translates Acerta's overall direction, values, } \\
\text { and purpose to the specific business domain. }\end{array}$ \\
\hline
\end{tabular}

Examples of VSM variety loops manifest at Acerta

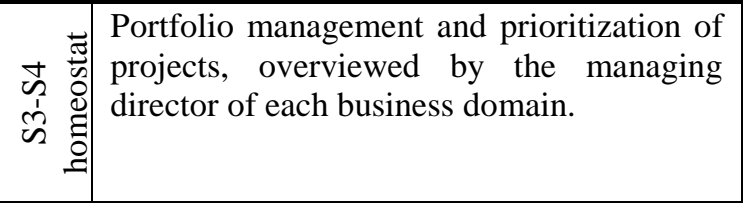

A clear flow in the recursions can be identified. In Acerta's corporate IT governance system (recursion 0 ), the identity of the system is held by the board of directors, which is taken into account by the executive committee during IT strategic planning and IT budgeting (viz. corporate variety loop S3-S4). Each ASC then translates what is being asked at executive committee-level to their specific business domain (recursion -1). The assigned part of the IT budget is also a given constraint for each business domain, for instance during their specific IT portfolio management and prioritization. In turn, the playing field of the MSC and PSCs that belong to a business domain is also determined by the business domain ASC, directly influencing the tasks at that level. We observed several links between recursion 0 and recursion -1 (organizational and business domain level respectively) at Acerta. First, the managing director of each business domain (S5 at each recursion -1) is also part of the executive committee ( $\mathrm{S} 3$ at recursion 0 ), which enables them to represent their specific business domain (or subsystem) at the corporate level. Second, the enterprise architect (S2 at each recursion -1), who is also the chair of the domain council of his/her business domain (S4 at each recursion -1), is also part of the EAF at the corporate level (S2/S4 at recursion 0 ), where they operationalize the coordination and intelligence functions of the VSM, bringing together the information they have from within their respective business domains. Third, the algedonic channel (viz. the communication channel used to filter out any information that requires the immediate attention of the metasystem) can be sourced in a PSC (S1 at recursion -1) and run its way back up to the executive committee and even the supervisory board (metasystem at recursion 0). This will happen when things go awry in a certain project. Another algedonic channel instance can be found in IT operations. When an incident classified as "very high" occurs (which will then most likely be sourced in recursion -2), the incident management system will automatically send an e-mail to the entire executive committee. Finally, business cases for investments can be brought from a business domain's ASC (S3 at recursion -1) to the executive committee or even the supervisory board at the corporate level. This happens when the IT budget 
is insufficient but the investment is considered to be of major strategic importance for Acerta.

These examples indicate that the underlying concept of recursion can be seen at work in Acerta's governance and management of IT system. As previously discussed, variety engineering should work at different levels of granularity (i.e. recursions). Nevertheless, the observer needs to decide on a scope of interest, which in our case consisted of the corporate level as well as the business domain level.

\subsubsection{IT governance dynamics: Enabling viability through variety engineering}

The establishment of the supervisory board-level monitoring committee for the "new wages engine" strategic IT project is an indication of the dynamic responding behavior of Acerta's IT governance system (a trait that is a requirement for viability), as this shows the tendency of the metasystem to respond dynamically to changes in operational variety. Specifically, we see that if the complexity/variety of $\mathrm{S} 1$ increases (in this case a very complex project in the pipeline), the metasystem responds to be able to deal with this increased variety (in this case by increasing the variety of response of system 5, mainly operationalized through the supervisory board at Acerta, by adding a dedicated monitoring committee, as well as a steering committee to deal with the higher overhead (because of the co-sourcing relation). When probed if such a board-level monitoring structure would be kept in use when the project was finished, the CIO said: "there is a 99\% chance that it will not, but it could definitely be back on the table when another major project arises." This is indeed an example of dynamic responding behavior of Acerta's metasystem in the realm of the governance and management of IT. Seeing as the VSM is a dynamic model, it is important to recognize that IT governance is a dynamic system. To put it in the words of the IT governance manager: "It should be avoided that the IT governance framework is unable to adapt to changing circumstances. It should not be fully prescribed in detail, as it should also take into account that there are differences between the different business domains for instance. Nevertheless, it always remains a hard requirement that all of the IT governance structures bring together business and IT people, to enable them working together closely, in order to safeguard business/IT alignment and close collaboration."

Dynamic behavior in response to changes in complexity/variety were observed for Acerta's governance and management of IT system in other areas as well. Several IT governance structures have variable meeting frequencies, depending on the complexity they have to deal with. For instance, the domain council within a given business domain tends to meet more frequently when there are more, or more complex, projects in the pipeline. A PSC tends to do the same thing depending on the phase the project is in. At the corporate level, the same was observed for the EAF, whose meeting frequency was recently increased from every two weeks to every week, as it was acknowledged that Acerta is currently in the process of undergoing some major strategic changes. Additionally, most IT governance structures are not only dynamic in meeting frequencies, but also in composition depending on the issues that need to be discussed. A domain council for instance tends to invite IT architects that are specialists in the technical aspects underlying the issues that are on the agenda for a given meeting. We also observed more dedicated enterprise architects for the more important business domains (in terms of IT budget). The enterprise architect was introduced as a new role within Acerta' contemporary governance and management of IT system. It was acknowledged that there was a need for a coordination mechanism that enabled the consistency of the whole, resulting in the implementation of the EAF. From a VSM point of view, this corporate S2 mechanism is needed for variety attenuation by the executive committee (corporate S3), as it works through mutual selfadjustments (and therefore does not require formal intervention - otherwise it would be a S3 mechanism that uses the command axis). A final point of dynamic behavior in Acerta's IT governance pertains to their business case process. The contents of business cases at Acerta appears to be a function of the investment size and type (e.g. formal business cases are only drafted for projects and investments), as well as the trigger event (e.g. business cases for legal/compliance projects are drafted in less detail).

All previous examples clearly show that Acerta's governance and management of IT system is not "set in stone”. Rather, it is dynamic in reacting to internal and external disturbances. This trait is the dynamic adaptation capability (i.e. variety engineering) that enables long-term viability.

\subsection{Conclusions and implications}

This paper presented Acerta's contemporary governance and management of IT system through the lens of the Viable System Model. The goal was to provide an empirical exemplar that would point in the direction of the applicability of the VSM for modelling 
IT governance. We found that Acerta's contemporary IT governance system maps well to the structure and logic of the VSM. Therefore, we propose that the VSM might provide an interesting blueprint to model governance and management of IT systems. Specifically, we propose that the VSM can provide a prescriptive account on which functions should be included in any IT governance system and how they should be interrelated, as well as the dynamics that emerge within such a system. This way, the VSM can be used to provide theoretical underpinnings (using (management) cybernetics as a kernel theory) for IT governance research, which enables theory building and the deduction of theory-based propositions. Therefore, this paper can also be seen as an exploratory step in the process of building a theory for IT governance.

All of the IT governance practices that we extracted from the interviews could be mapped to the VSM systems and variety loops, at different levels of recursion. This resulted in the observation that Acerta operationalized the five necessary and sufficient VSM systems in at least two recursions (i.e. corporate level and business domain level governance and management of IT). Furthermore, this case study discussed the application of key VSM concepts (e.g. recursion and variety/complexity engineering to enable viability) in Acerta's governance and management of IT system. Acerta's system was found to be dynamic in response to changes in variety/complexity, as is required in terms of the VSM. The case study presented in this paper can therefore be seen as a good-practice exemplar of how a real-world governance and management of IT system should work, using the VSM as a theoretical lens.

\section{Limitations and opportunities for future research}

Future research steps might include a longitudinal analysis of the transformation of an IT governance system, e.g. through action research. The prior situation can then be compared to the new situation (which was designed according to the VSM) in terms of IT governance effectiveness. Alternatively, "extreme case" research can be conducted, by theoretically sampling on maximal variation on (a) certain dependent variable(s). Potential differences in IT governance effectiveness can then be related to potential differences at the level of implementation/operationalization of the VSM systems. Finally, design science research can be conducted in order to present good-practice IT governance solutions for a certain context (e.g. interorganizational, SME etc.), extensively using practitioner knowledge as well as the IT governance body of knowledge, while rigorously adhering to the VSM structure and concepts.

\section{References}

[1] K. C. Laudon and J. P. Laudon, Management Information Systems, 14/E. Pearson, 2015.

[2] E. Valentine and G. Stewart, "Enterprise Business Technology Governance: Three Competencies to Build Board Digital Leadership Capability,” in 2015 48th Hawaii International Conference on System Sciences, 2015, pp. 4513-4522.

[3] E. Valentine and G. Stewart, "The emerging role of the Board of Directors in enterprise business technology governance,” Int. J. Discl. Gov., vol. 10, no. 4, pp. 346-362, Apr. 2013.

[4] S. De Haes and W. Van Grembergen, Enterprise governance of information technology, second edition. Springer, 2015.

[5] R. R. Peterson, "Integration Strategies and Tactics for Information Technology Governance,” in Developing Successful ICT Strategies, H. Rahman, Ed. IGI Global, 2004, pp. 240-280.

[6] ISACA, “COBIT 5: A Business Framework for the Governance and Management of Enterprise IT," 2012.

[7] P. Weill and J. W. Ross, IT Governance: How Top Performers Manage IT Decision Rights for Superior Results. Harvard Business Press, 2004.

[8] S. P.-J. Wu, D. W. Straub, and T.-P. Liang, "How information technology governance mechanisms and strategic alignment influence organizational performance: insights from a matched survey of business and IT managers,” MIS Q., vol. 39, no. 2, 2015.

[9] G. S. Kearns and R. Sabherwal, "Strategic Alignment Between Business and Information Technology: A Knowledge-Based View of Behaviors, Outcome, and Consequences,” Journal of Management Information Systems. Routledge, 09-Dec-2007.

[10] W. Raghupathi, "Corporate Governance of IT: A Framework For Development,” Commun. ACM, vol. 50, no. 8, pp. 94-99, Aug. 2007.

[11] T. H. Davenport, "Putting the enterprise into the enterprise system.,” Harv. Bus. Rev., vol. 76, no. 4, pp. 121-131, Jan. 1998.

[12] C. Herring and S. Kaplan, "The viable system architecture," in Proceedings of the 34th Annual Hawaii International Conference on System Sciences, 2001, p. 10.

[13] R. C. Conant and W. R. Ashby, "Every good regulator of a system must be a model of that system,” Int. J. Syst. Sci., vol. 1, no. 2, pp. 89-97, Mar. 1970.

[14] J. Richter and D. Basten, “Applications of the 
Viable Systems Model in IS Research -- A Comprehensive Overview and Analysis,” in 2014 47th Hawaii International Conference on System Sciences, 2014, pp. 4589-4598.

[15] G. Karayaz, C. B. Keating, and M. Henrie, "Designing Project Management Systems," in 2011 44th Hawaii International Conference on System Sciences, 2011, pp. 1-10.

[16] M. Laumann and C. Rosenkranz, “Analysing Information Flows for Controlling Activities within Supply Chains: An Arvato (Bertelsmann) Business Case,” ECIS 2008 Proceedings. 2008.

[17] G. B. Gokhale and D. A. Banks, "Organisational Information Security: A Viable System Perspective," in AISM, 2004.

[18] J. Peppard, "The Application of the Viable Systems Model to Information Technology Governance,” ICIS 2005 Proceedings. 2005.

[19] E. Lewis and G. Millar, "The Viable Governance Model - A Theoretical Model for the Governance of IT,” in 2009 42nd Hawaii International Conference on System Sciences, 2009, pp. 1-10.

[20] R. Skeivys, "Governance of IT and cybernetics," in Norbert Wiener in the 21st Century (21CW), 2016 IEEE Conference on, 2016, pp. 46-49.

[21] W. Van Grembergen and S. De Haes, Enterprise Governance of Information Technology: Achieving Strategic Alignment and Value. Springer, 2009.

[22] R. Nolan and F. McFarlan, "Information technology and the board of directors," Harv. Bus. Rev., vol. 83, no. 10, p. 96-+, Oct. 2005.

[23] A. Prasad, P. Green, and J. Heales, “On IT governance structures and their effectiveness in collaborative organizational structures," Int. J. Account. Inf. Syst., vol. 13, no. 3, pp. 199-220, Sep. 2012.

[24] S. De Haes and W. Van Grembergen, “An Exploratory Study into IT Governance Implementations and its Impact on Business/IT Alignment,” Inf. Syst. Manag., vol. 26, no. 2, pp. 123-137, Apr. 2009.

[25] R. Huang, R. W. Zmud, and R. L. Price, "Influencing the effectiveness of IT governance practices through steering committees and communication policies,” Eur. J. Inf. Syst., vol. 19, no. 3, pp. 288-302, Mar. 2010.

[26] C. V. Brown, "Examining the Emergence of Hybrid IS Governance Solutions: Evidence From a Single Case Site,” Inf. Syst. Res., vol. 8, no. 1, pp. 69-94, Mar. 1997.

[27] V. Sambamurthy and R. Zmud, “Arrangements for Information Technology Governance: A Theory of Multiple Contingencies," Management Information Systems Quarterly, vol. 23, no. 2. 1999.

[28] C. V. Brown and J. S. Renwick, “Alignment of the IS organization,” ACM SIGMIS Database, vol. 27, no. 4, pp. 25-33, Sep. 1996.

[29] S. Ali and P. Green, "Effective information technology (IT) governance mechanisms: An IT outsourcing perspective,” Inf. Syst. Front., vol. 14, no. 2, pp. 179-193, Jun. 2009.

[30] R. R. Peterson, “Crafting Information Technology Governance,” Inf. Syst. Manag., vol. 21, no. 4, pp. 7-22, Sep. 2004.

[31] L. von Bertalanffy, General System Theory. New York: George Brazillier Inc., 1968.

[32] M. Yolles, Management Systems. London: Financial Times Ltd., 1999.

[33] G. Preece, D. Shaw, and H. Hayashi, "Using the Viable System Model (VSM) to structure information processing complexity in disaster response,” Eur. J. Oper. Res., vol. 224, no. 1, pp. 209-218, Jan. 2013.

[34] R. Espejo and A. Reyes, Organizational Systems: Managing Complexity with the Viable System Model. Springer-Verlag Berlin Heidelberg, 2011.

[35] R. L. Flood and M. C. Jackson, Creative problem solving. Chichester: Wiley, 1991.

[36] S. Beer, Brain of the firm. London: Allen Lane, 1972.

[37] S. Beer, The heart of enterprise. John Wiley \& Sons, 1979.

[38] S. Beer, Diagnosing the system for organizations. West Sussex: John Wiley \& Sons, 1985.

[39] S. Beer, Brain of the firm, second edition. Chichester: John Wiley, 1981.

[40] S. Beer, Cybernetics and Management. London: The English Universities Press, 1959.

[41] R. Anderton, "The need for formal development of the VSM," in The Viable System Model: Interpretations and Applications of Stafford Beer's VSM, R. Espejo and R. Harnden, Eds. John Wiley \& Sons, 1989, pp. 39-50.

[42] J. Mingers and L. White, “A review of the recent contribution of systems thinking to operational research and management science,” Eur. J. Oper. Res., vol. 207, no. 3, pp. 1147-1161, Dec. 2010.

[43] D. R. Shaw, B. Snowdon, C. P. Holland, P. Kawalek, and B. Warboys, "The viable systems model applied to a smart network: the case of the UK electricity market,” J. Inf. Technol., vol. 19, no. 4, pp. 270-280, Oct. 2004.

[44] M. C. Jackson, Systems methodology for the management sciences. New York: Plenum Press, 1991.

[45] R. Espejo, “The VSM revisited," in The Viable System Model: Interpretations and Applications of Stafford Beer's VSM, R. Espejo and R. Harnden, Eds. John Wiley \& Sons, 1989, pp. 77-100.

[46] Y. A. Pollalis and N. K. Dimitriou, "Knowledge management in virtual enterprises: A systemic multi-methodology towards the strategic use of information,” Int. J. Inf. Manage., vol. 28, no. 4, pp. 305-321, Aug. 2008.

[47] W. Ashby, An Introduction to Cybernetics. London: Chapman \& Hall, 1956.

[48] R. Espejo and A. Gill, "The Viable System Model as a Framework for Understanding Organizations.” 1997.

[49] D. S. Preston and E. Karahanna, "Antecedents of IS Strategic Alignment: A Nomological Network,” 
Inf. Syst. Res., vol. 20, no. 2, pp. 159-179, Jun. 2009.

[50] R. K. Yin, Case Study Research: Design and Methods, 5th edition. SAGE Publications, Inc., 2014. 